\title{
Proteome changes in the small intestinal mucosa of growing pigs with dietary supplementation of non-starch polysaccharide enzymes
}

Jize Zhang ${ }^{1,2}$, Yang Gao ${ }^{3}$, Qingping Lu², Renna Sa² and Hongfu Zhang ${ }^{2 *}$

\begin{abstract}
Background: Non-starch polysaccharide enzymes (NSPEs) have long been used in monogastric animal feed production to degrade non-starch polysaccharides (NSPs) to oligosaccharides in order to promote growth performance and gastrointestinal (GI) tract health. However, the precise molecular mechanism of NSPEs in the improvement of the mammalian small intestine remains unknown.

Methods: In this study, isobaric tags were applied to investigate alterations of the small intestinal mucosa proteome of growing pigs after 50 days of supplementation with 0.6\% NSPEs (mixture of xylanase, $\beta$-glucanase and cellulose) in the diet. Bioinformatics analysis including gene ontology annotation was performed to determine the differentially expressed proteins. A protein fold-change of $\geq 1.2$ and a $P$-value of $<0.05$ were selected as thresholds.

Results: Dietary supplementation of NSPEs improved the growth performance of growing pigs. Most importantly, a total of 90 proteins were found to be differentially abundant in the small intestinal mucosa between a control group and the NSPE group. Up-regulated proteins were related to nutrient metabolism (energy, lipids, protein and mineral), immunity, redox homeostasis, detoxification and the cell cytoskeleton. Down-regulated proteins were primarily related to transcriptional and translational regulation. Our results indicate that the effect of NSPEs on the increase of nutrient availability in the intestinal lumen facilitates the efficiency of nutrient absorption and utilization, and the supplementation of NSPEs in growing pigs also modulates redox homeostasis and enhances immune response during simulating energy metabolism due to a higher uptake of nutrients in the small intestine.
\end{abstract}

Conclusions: These findings have important implications for understanding the mechanisms of NSPEs on the small intestine of pigs, which provides new information for the better utilization of this feed additive in the future.

Keywords: Non-starch polysaccharide enzymes, Small intestinal mucosa, Proteomics, Growing pigs

\section{Background}

Many cereals such as soybean and wheat contain up to $15 \%$ non-starch polysaccharides (NSPs) in their outer or inner cell walls [1]. Monogastric animals lack enzymes to degrade the cell wall and NSP in these feeds. Thus, these anti-nutritive factors may interfere with digestion, nutrient absorption, and intestinal tract health by encapsuling

\footnotetext{
* Correspondence: zhanghf6565@vip.sina.com

${ }^{2}$ State Key Laboratory of Animal Nutrition, Institute of Animal Sciences, Chinese Academy of Agricultural Sciences, Beijing 100193, People's Republic of China

Full list of author information is available at the end of the article
}

starch and protein, as well as increase the viscosity of the chymus, which may elevate the proliferation of pathological bacteria in the small intestine and reduce the feed conversion ratio of monogastric livestock species [2-4].

The supplementation of exogenous enzymes such as xylanases and $\beta$-glucanases in pig diets may facilitate the hydrolysis of the main NSPs and increase the utilization of available raw materials $[5,6]$. Adding exogenous enzymes to cereal diets improves both nutrient digestibility and growth performance in pigs $[7,8]$. However, the exact molecular mechanisms of NSPEs, particularly in the gastrointestinal (GI) tract, are unknown [9]. There are several 
indications that exogenous enzymes may function in the GI tract of animals to aid digestion. The supplementation of NSPEs in the diets could increase the activities of certain types of digestive enzymes in vivo including protease, trypsin, and $\alpha$-amylase $[2,4,10]$. These enzymes reduce the degradation of NSPs within the small intestine, thereby decreasing the viscosity of the digesta, which leads to a reduced bacterial load in the gut, especially potential pathogens [11]. Furthermore, the degradation of NSPs due to the supplementation of NSPEs promotes the higher availability of digestible nutrients such as energy substrates [12]. Additionally, the intestinal morphological structure and some physiological functions in animals benefit from the improvement of the changing intestinal environment due to the supplementation of NSPEs. Some research demonstrated that intestinal morphologies, including the villus height, the ratio of villus height to crypt depth, and the number of crypts and goblet cells, were changed due to the addition of xylanases alone or multiple enzymes $[13,14]$. In addition to the effects of NSPEs observed on the GI tract, alterations of blood parameters related to the nutrient metabolism were also noted [15].

Previous studies reported that diet composition affected gene expression in animals $[9,16]$. It is assumed that the improvement of the intestinal environment due to the supplementation of NSPEs in the diet may influence the gene expression and subsequent protein expression of epithelial-cell nutrient transporters in the GI tract mucosa, which has not been studied before. However, RNA editing and numerous options for posttranslational modifications should be taken into account $[17,18]$. Hence, elucidation protein expression is important [19].

It is impractical to simultaneously measure all protein expression in the GI mucosa by classical method, such as western blotting. More research has yielded high throughput mass spectrometric proteomic technologies that can simultaneously detect hundreds of proteins $[20,21]$. A proteomic analysis of the rat small intestinal proteome showed the presence of previously unrecognized proteins involved in various functions including the absorption and transport of nutrients and the maintenance of cell structure, as well as intestinal molecular chaperones [22]. There remains a great need to pursue proteomic technology to elucidate the beneficial effects of NSPEs in the GI tract mucosa. Therefore, we utilized a label-based iTRAQ (isobaric tags for relative and absolute quantitation) method, followed by LC-MS/MS, to quantitate proteins that are differentially induced in the small intestinal mucosa of growing pigs supplemented with NSPEs in the diet.

\section{Methods}

\section{Enzyme preparation}

The NSP enzyme mixture preparation supplemented in the diet was provided by the State Key Laboratory of
Animal Nutrition, Institute of Animal Sciences, Chinese Academy of Agricultural Sciences (Beijing, China); the mixture contained $7 \times 10^{5} \mathrm{U} / \mathrm{g}$ xylanase activity (EC 3.2.1.8), $1 \times 10^{5} \mathrm{U} / \mathrm{g} \beta$-glucanase activity (EC 3.2.1.6), and $9000 \mathrm{U} / \mathrm{g}$ cellulase activity (EC 3.2.1.4). The activities of the enzymes used in the present study was measured according the methods mentioned in previous research [23].

\section{Animals and treatments}

Forty-eight crossbred (Duroc $\times$ Landrace $\times$ Large White) growing pigs had similar initial body weights $(39.18 \pm$ $0.98 \mathrm{~kg}$ ); the pigs were obtained from a commercial farm in Beijing (Shunliang pig farm, Beijing). The pigs were randomly divided into two groups according to their littermates, sex and mean initial body weights with four replicates in each group and six pigs in each replicate (half females and half males). The following two groups were a control group (CTRL, basal diet) and a treatment group (NSPE, basal diet $+0.6 \%$ NSP enzymes). The amount of NSPEs supplementation in the present study was based on the previous results from our group [24]. Both diets were formulated to meet NRC (2012) recommendations (Table 1). All pigs were kept in eight adjacent pens covered in a fermentation bed facility. Feed and water were provided ad libitum during the 50 day experimental period. The individual pig weight and feed intake were recorded at the initiation and the termination of the experiment for the measurement of the average daily gain (ADG), average daily feed intake (ADFI) and feed conversion ratio (FCR). All procedures involving animals were evaluated and approved by the Animal Ethics Committee of the Institute of Animal Sciences, Chinese Academy of Agricultural Sciences.

\section{Sample collection}

At the end of the experiment (Day 50), all pigs were weighted after $12 \mathrm{~h}$ of fasting. One pig per replicate, a total of eight pigs $(n=8)$, were sacrificed by $\mathrm{CO}_{2}$ asphyxiation and then exsanguinated. Blood samples were obtained from the cervical vein by syringe before sacrifice. The whole blood was centrifuged at $2000 \mathrm{~g}$ for $30 \mathrm{~min}$ at $4{ }^{\circ} \mathrm{C}$, followed by centrifugation at $400 \mathrm{~g}$ for $10 \mathrm{~min}$ at $4{ }^{\circ} \mathrm{C}$. Then, the resulting supernatant was collected as sera samples, which were stored at $-20{ }^{\circ} \mathrm{C}$ for further analysis. A $20-\mathrm{cm}$ tissue section was rapidly excised at $50 \%$ of the length of the small intestine, rinsed with cold phosphate buffer saline, and blotted dry on paper. Mucosa from this small intestine section was sequentially obtained by careful scraping of the mucosal layer using a glass microscope slide as previously described [25]. Then, the collected mucosal samples were snap-frozen in liquid nitrogen and stored at $-80{ }^{\circ} \mathrm{C}$ for proteomic analysis. 
Table 1 Composition of the basal diet and calculated proximate composition of the diet

\begin{tabular}{ll}
\hline Ingredients & Proportion (\%) \\
\hline Corn & 70.70 \\
Soybean meal & 19.82 \\
Soybean oil & 2.10 \\
Wheat bran & 5.00 \\
Limestone & 0.51 \\
Calcium hydrophosphate & 0.56 \\
L-Lysine & 0.01 \\
Sodium chloride & 0.30 \\
Premix & 1.00 \\
Total & 100 \\
Nutrient & \\
ME & $13.65(\mathrm{MJ} / \mathrm{kg})$ \\
Ether extract (EE) & 4.82 \\
Crude protein (CP) & 15.50 \\
Calcium & 0.50 \\
Total phosphorus & 0.45 \\
Available phosphorus & 0.24 \\
Total lysine & 0.75 \\
Total methionine & 0.25 \\
\hline
\end{tabular}

${ }^{a}$ All data is expressed in $\mathrm{g} / \mathrm{kg}$ dry weight except for metabolizable energy (ME) in $\mathrm{MJ} / \mathrm{kg}$. The amounts of nutrient were estimated based on the NRC 11th ed. swine feedstuff composition table

${ }^{b}$ Providing the following ( $\mathrm{g} / \mathrm{kg}$ fresh weight), Vitamin $\mathrm{A}, 8250 \mathrm{IU}$; Vitamin $\mathrm{D}_{3}$ : $825 \mathrm{IU}$; Vitamin E: $40 \mathrm{IU}$; Vitamin $\mathrm{K}_{3}, 4.0 \mathrm{mg}$; Vitamin $\mathrm{B}_{1}, 1.0 \mathrm{mg}$; Vitamin $\mathrm{B}_{2}$ $5.0 \mathrm{mg}$; Vitamin $\mathrm{B}_{6}, 2.0 \mathrm{mg}$; Vitamin $\mathrm{B}_{12}, 25 \mu \mathrm{g}$; choline chloride, $600 \mathrm{mg}$; nicotinic acid, $35 \mathrm{mg}$; folic acid, $2.0 \mathrm{mg}$; biotin, $4.0 \mathrm{mg} ; \mathrm{Cu}, 50.0 \mathrm{mg}$; $\mathrm{Fe}$, 80.0 mg; Zn, 100.0 mg; Mn, 25.0 mg; Se, 0.15 mg; l, 0.5 mg

\section{Serum biochemical analyses}

Important serum biochemical parameters, including alanine aminotransferase (ALT), aspartate aminotransferase (AST), total protein (TP), alkaline phosphatase (ALP), glucose (GLU), and creatine kinase (CK), were analyzed using an automatic biochemical analyzer (Hitachi 7020, Tokyo, Japan). Serum levels of total superoxide dismutase (T-SOD) and immunoglobulin G (IgG) were measured using a corresponding kit (Nanjing Jiancheng Bioengineering Institute, Nanjing, China) according to the manufacturer's instructions.

\section{Protein extraction and sample preparation}

Small intestinal mucosa samples $(500 \mu \mathrm{g})$ were ground in liquid nitrogen using a Dounce glass grinder. Grinded powder was precipitated with $10 \%$ trichloroacetic acid (TCA) $(\mathrm{w} / \mathrm{v})$ and $90 \%$ ice-cold acetone at $-20{ }^{\circ} \mathrm{C}$ for $2 \mathrm{~h}$. The precipitate was obtained by centrifugation at 20,000 $\mathrm{g}$ for $30 \mathrm{~min}$ at $4{ }^{\circ} \mathrm{C}$ and subsequently washed with ice-cold acetone. Then, the precipitate was lysed in lysis buffer [8 M urea, 30 mM 4-(2-hydroxyethyl)-1-piperazineethanesulfonic acid (HEPES), $1 \mathrm{mM}$ phenylmethanesulfonyl fluoride (PMSF), $2 \mathrm{mM}$ ethylene diamine tetraacetic acid (EDTA), and $10 \mathrm{mM}$ dithiothreitol (DTT)]. The crude tissue extracts were centrifuged to remove the remaining debris. The tissue lysates were reduced for $1 \mathrm{~h}$ at $56{ }^{\circ} \mathrm{C}$ in a water bath using $10 \mathrm{mM}$ DTT and then alkylated with $55 \mathrm{mM}$ iodoacetamide for $1 \mathrm{~h}$ in the dark. Afterwards, the lysates were precipitated by adding four volumes of prechilled acetone. The pellets were then washed three times with pre-chilled pure acetone and resuspended in the buffer (50\% TEAB and $0.1 \%$ SDS). The centrifugation was repeated to remove the undissolved pellets. Subsequently, protein quantitation was determined using a Bio-Rad Bradford Protein Assay Kit (Hercules, CA, USA). Each sample was digested with modified sequence grade trypsin (Promega Corporation, Madison, WI) at a 1: 30 ratio (3.3 $\mu \mathrm{g}$ trypsin : $100 \mu \mathrm{g}$ target) overnight at $37^{\circ} \mathrm{C}$. Each isobaric tag $(113,114,115,116,117,118,119$, and 121) was solubilized in $70 \mu \mathrm{L}$ isopropanol and then added to each respective sample (4 samples per group). Incubation continued for $2 \mathrm{~h}$ at room temperature.

\section{Strong cation exchange chromatography}

The strong cation exchange fractionation was performed according to a previous report [26] with slight modification. Briefly, $800 \mu \mathrm{g}$ of labeled sample was loaded onto a strong cation exchange column (Phenomenex Luna SCX 100A) installed in an Agilent 1100 (Santa Clara, CA) system and equilibrated with buffer A (25\% acetonitrile and $10 \mathrm{mM} \mathrm{KH}{ }_{2} \mathrm{PO}_{4}, \mathrm{pH} 3.0$ ). The peptides were separated by a linear gradient of buffer $\mathrm{B}(25 \%$ acetonitrile, $2 \mathrm{M} \mathrm{KCl}$ and $10 \mathrm{mM} \mathrm{KH}_{2} \mathrm{PO}_{4}, \mathrm{pH} \mathrm{3.0)}$ according to this procedure (increasing to $5 \%$ after $41 \mathrm{~min}, 50 \%$ after $66 \mathrm{~min}$ and $100 \%$ after $71 \mathrm{~min}$ with a flow rate of $1 \mathrm{ml} /$ min). Elution was monitored by setting the absorbance at $214 \mathrm{~nm}$. A total of 10 fractions were obtained, then desalted with a Strata X C18 column (Phenomenex) and dried under a vacuum. The pellets were resuspended by adding $0.1 \%$ formic acid before the LC-MS/MS run.

\section{Mass spectrometry}

LC-MS/MS was conducted according to a previous report [27], and the detailed process and parameters are shown in Additional file 1.

\section{Data processing and protein quantification}

All the detailed parameters are shown in the Supporting Information (Additional file 1). MS/MS data for iTRAQ protein identification and quantitation were analyzed using Proteome Discover 1.3 (Thermo Fisher Scientific, Bremen, Germany) and in-house MASCOT software (Matrix Science, London, UK; Version 2.3.0) against the database Uniprot_pig (Apr. 11th, 2014). Median ratio normalization was performed in intra-sample channels to normalize each channel across all proteins. Protein 
quantitative ratios for each iTRAQ labeled sample were obtained, using a sample in the control group (sample tagged with 113) as the denominator. Quantitative ratios were then log transformed to base two and presented as the fold change relative to the denominator in the control group for final quantitative testing. Differentially expressed proteins were identified using Student's $t$-test corrected for multiple testing using the Benjamini and Hochberg correction [21, 25, 28, 29]. Based on above the relative quantification, statistical analysis, and a number of previous reports regarding to iTRAQ experiments [29-31], we set a 1.2-fold change or greater as the threshold for differentially expressed proteins.

\section{Bioinformatics analysis and validation of protein expression}

The databases and software for bioinformatics analysis are shown in Additional file 1. Real-time qPCR was used to verify six small intestinal mucosal proteins of differential abundance at the mRNA level. All detailed procedures are described in the Supporting Information (Additional file 1). The primer sequences used in this study are shown in Additional file 2: Table S1.

\section{Statistical analysis}

The data for growth parameters, serum parameters, and gene expression were analyzed by one-way ANOVA using block as a covariate (SAS Version 9.2, SAS institute Inc., Cary, NC) according the previous studies [21,31], and a $t$ test was used for independent samples in MS data analysis. A group difference was assumed statistically significant when $P<0.05$.

\section{Results}

\section{Growth performance of growing pigs}

During the entire experimental period (50 days), NSPE pigs had $15.5 \%$ greater ADG $(P<0.05)$ compared with the control group; however, the ADFI between the two groups was not significantly different $(P>0.05)$. It is notable that pig fed NSPEs had an $8.7 \%$ greater FCR compared with the control group $(P<0.05$; Table 2$)$.

\section{Serum parameters of growing pigs}

In NSPE pigs, serum concentration of CK was significantly lower $(P<0.05)$ than the control group (Table 3). Furthermore, the serum concentrations of T-SOD, IgG, and glucose were significantly elevated compared with the control group $(P<0.05)$ (Table 3). Serum levels of TP, ALT and AST were similar between the two groups (Table 3).

\section{Identification and comparison of proteins of differential abundance}

Using iTRAQ analysis, a total of 2634 proteins were identified within the FDR (false discovery rate) of $1 \%$
Table 2 Effects of NSP enzymes on growth performance of growing pigs

\begin{tabular}{lcll}
\hline & \multicolumn{3}{l}{ Groups } \\
\cline { 2 - 4 } & Control & Treatment & $P$ value \\
\hline Initial weight $(\mathrm{kg})$ & $38.80 \pm 0.99$ & $39.55 \pm 0.63$ & 0.1245 \\
Final weight $(\mathrm{kg})$ & $74.04 \pm 1.77^{\mathrm{b}}$ & $78.42 \pm 1.06^{\mathrm{a}}$ & 0.0318 \\
${\text { ADG }(\mathrm{kg} / \mathrm{d})^{\mathrm{c}}}^{\mathrm{A}}$ & $0.71 \pm 0.05^{\mathrm{b}}$ & $0.82 \pm 0.05^{\mathrm{a}}$ & 0.0437 \\
ADFI $(\mathrm{kg} / \mathrm{d})^{\mathrm{d}}$ & $1.97 \pm 0.09$ & $2.07 \pm 0.06$ & 0.0423 \\
FCR $(\mathrm{kg} \mathrm{feed} / \mathrm{kg}$ weight gain) & $2.77 \pm 0.02^{\mathrm{a}}$ & $2.53 \pm 0.03^{\mathrm{b}}$ & 0.0352 \\
\hline
\end{tabular}

$\mathrm{a}, \mathrm{b}$ Values within a column having different superscript letters indicate a significant difference at $P<0.05$. Numbers are mean \pm S.D. $(n=24$ for ADG; $n=4$ for ADFI and FCR)

${ }^{\mathrm{C}} \mathrm{ADG}=$ average daily gain

${ }^{\mathrm{d}} \mathrm{ADFI}=$ average daily feed intake

${ }^{\text {e }} \mathrm{FCR}=$ feed conversion ratio

(Additional file 3: Table S2). Following statistical analysis, 104 proteins were found to be differentially expressed in the small intestinal mucosa between CTRL and NSPE pigs, with 43 up-regulated and 61 downregulated (Additional file 4: Table S3).

A total of 90 proteins of differential abundance were grouped into eight classes based on putative functions: transcriptional and translational regulation (44.4\%), miscellaneous (16.7\%), redox homeostasis and detoxification (10.0\%), immune response and inflammation $(8.9 \%)$, energy metabolism $(7.8 \%)$, protein metabolism and modification (5.6\%), lipid metabolism (3.3\%), and cell cytoskeleton (3.3\%) (Fig. 1). Those related to transcriptional and translational regulation, redox homeostasis, and immune response were predominant, accounting for approximately $63 \%$ of the differentially expressed proteins. A comparison

Table 3 Effect of NSPEs on serum biochemical parameters of growing pigs

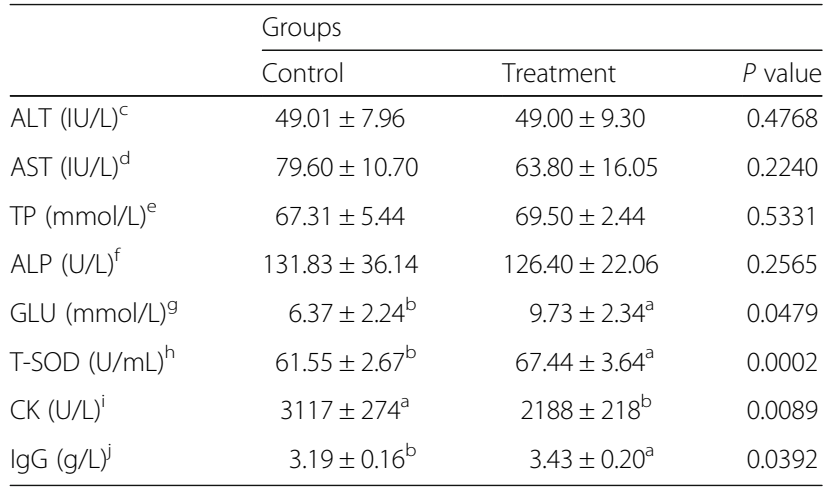

a, balues within a column not sharing a common superscript letter indicate significant difference at $P<0.05$. Numbers are means \pm S.D. $(n=4)$

${ }^{\mathrm{C}} \mathrm{ALT}=$ alanine aminotransferase

${ }^{\mathrm{d}} \mathrm{AST}=$ aspartate aminotransferase

${ }^{\mathrm{e}} \mathrm{TP}=$ total protein

${ }^{\mathrm{f}} \mathrm{ALP}=$ alkaline phosphatase

${ }^{g} \mathrm{GLU}=$ glucose

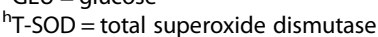

${ }^{\mathrm{i}} \mathrm{CK}=$ creatine kinase

${ }^{\mathrm{j}} \mathrm{lgG}=$ immunoglobulin $\mathrm{G}$ 

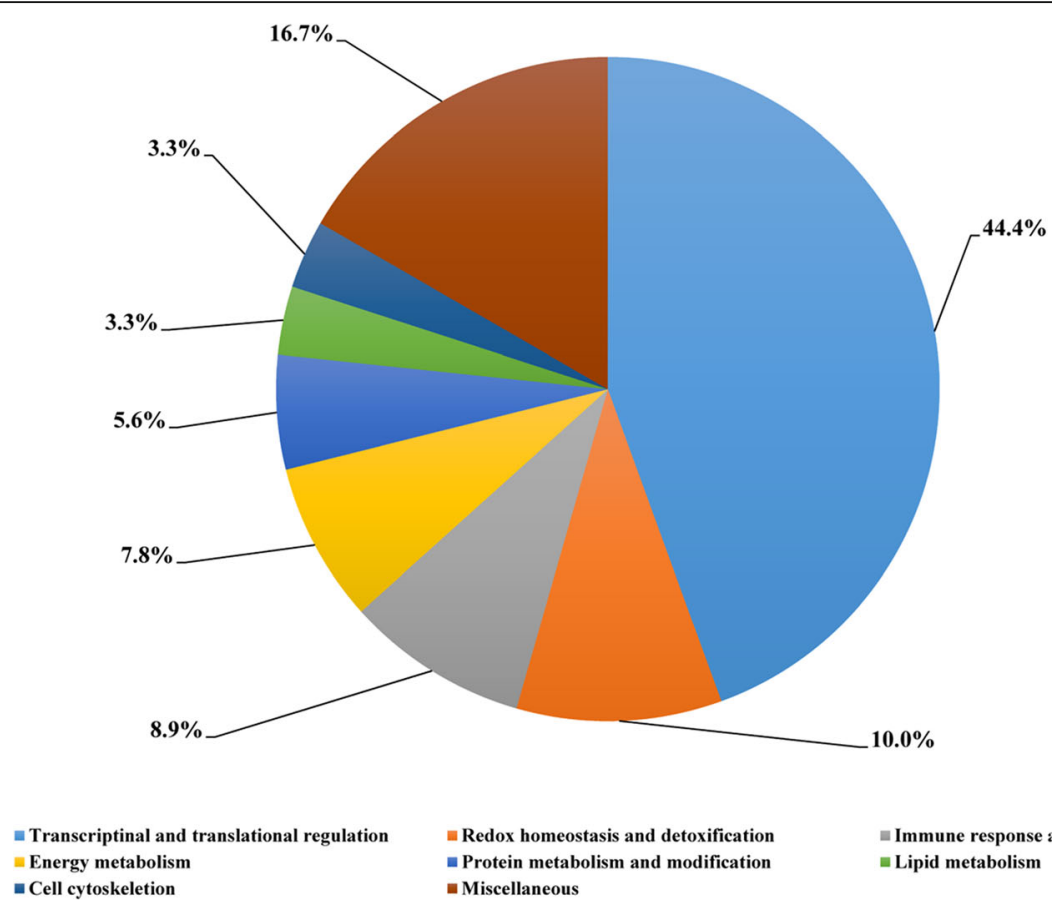

- Redox homeostasis and detoxification - Protein metabolism and modification

Elmmune response and inflammation Miscellaneous

= Lipid metabolism

Fig. 1 Functional classification of the proteins of differential abundance identified from the small intestinal mucosa of growing pigs supplemented with NSPE

of proteins of differential abundance with functional groupings between the two groups indicated that a smaller number of protein species were up-regulated in NSPE pigs (36 versus 54) (Table 4).

\section{GO annotations of proteins of differential abundance}

In the cellular component group, the differentially expressed proteins were concentrated in the intracellular part and membrane-bounded organelles (Fig. 2). In the molecular functional group, the differentially expressed proteins that are binding proteins (protein, nucleotide, or nucleic acid binding) and metabolic enzymes (hydrolase, oxidoreductase, or transferase activity) were ranked at the top of the category (Fig. 2). In the biological process category, the proteins that participate in cellular process (organelle organization process), metabolic process (nitrogen compound metabolic and biosynthetic process), and biological regulation (transcriptional and translational regulation, redox homeostasis, and immune response) had the highest ratios among the differentially expressed proteins.

\section{Validation of proteins of differential abundance}

Six differentially expressed proteins superoxide dismutase (SOD1) involved in redox homeostasis; calmodulin (CALM1) involved in calcium ion binding; MHC class I antigen (SLA-1) involved in immune response; acylcoenzyme A oxidase (ACOX1) involved in energy metabolism; 40S ribosomal protein S6 (RPS6) involved in transcriptional and translational regulation; and apolipoprotein C-III (APOC3) involved in lipid absorption, were selected for the validation of proteomic data at the mRNA level using qPCR (Fig. 3). Most protein levels were consistent with their mRNA expression levels, except for RPS6.

\section{Discussion}

The benefit of NSPEs supplementation is well recognized in monogastric animal production; NSPEs supplementation promotes growth performance and GI tract health, including the efficiency of nutrient utilization $[2,3,8]$. A number of studies have proven that the addtion of NSPEs to the diet reduces digesta viscosity by the partial or complete hydrolysis of soluble NSPs, which triggers the changes in microbial composition, especially the reduction of the amount of pathological bacteria within the small intestine [11, 32]. Moreover, the supplementation of NSPEs could increase the nutrient availability in the intestinal lumen (for example, energy substrates and proteins) [12,33]. All above effects of NSPE supplementation are due to the improvements of the intestinal environment. However, it is still largely unknown how the small intestinal mucosa of the hosts responds to alterations in the luminal environment triggered by the addition of NSPEs. The present study marks the first time that the well-established quantitative iTRAQ label-based technology was applied for the proteomic analysis of the small intestinal mucosa of growing pigs with dietary supplementation of NSPEs. Various functional groupings of differentially expressed mucosal proteins 
Table 4 List of differentially expressed proteins in small intestinal mucosal samples from treatment group and control group

\begin{tabular}{|c|c|c|c|c|c|c|c|}
\hline Accession $^{a}$ & Description $^{\text {b }}$ & Gene symbol & Score ${ }^{c}$ & $\begin{array}{l}\text { Pep. } \\
\text { No }^{d}\end{array}$ & $\begin{array}{l}\log _{2} \\
\text { fold } \\
\text { change }\end{array}$ & $P$-value & Biological process GO term \\
\hline \multicolumn{8}{|c|}{ Transcriptional and translational regulation } \\
\hline F1S419 & $\begin{array}{l}\text { Uncharacterized protein OS = Sus scrofa GN = SF3B3 } \\
P E=4 S V=2-\left[F 1 S 419 \_P I G\right]\end{array}$ & None & 85.61 & 3 & -0.37 & 0.0007 & RNA binding \\
\hline K9J4VO & $\begin{array}{l}\text { U5 small nuclear ribonucleoprotein } 200 \mathrm{kDa} \text { helicase } \\
\text { OS = Sus scrofa GN = SNRNP200 PE = } 2 \mathrm{SV}=1 \text { - } \\
\text { [K9J4VO_PIG] }\end{array}$ & SNRNP200 & 248.18 & 9 & -0.32 & 0.0012 & Nucleic acid binding \\
\hline F2Z5Q6 & $\begin{array}{l}40 S \text { ribosomal protein S6 (Fragment) OS = Sus scrofa } \\
\mathrm{GN}=\mathrm{RPS6} \mathrm{PE}=3 \mathrm{SV}=2-[\mathrm{F} 2 \mathrm{Z} 5 \mathrm{Q} 6 \mathrm{PIG}]\end{array}$ & RPS6 & 140.42 & 4 & -0.81 & 0.0013 & $\begin{array}{l}\text { Structural constituent of } \\
\text { ribosome }\end{array}$ \\
\hline F1SD96 & $\begin{array}{l}\text { Uncharacterized protein (Fragment) OS = Sus scrofa } \\
G N=\text { RAD23A PE }=4 S V=1-[\text { F1SD96_PIG] }\end{array}$ & RAD23A & 85.25 & 3 & 1.06 & 0.0026 & Nucleotide excision repair \\
\hline F1S8K5 & $\begin{array}{l}\text { Uncharacterized protein OS = Sus scrofa GN }= \\
\text { SUPT16H PE }=4 \text { SV }=1-\text { [F1S8K5_PIG] }\end{array}$ & SUPT16H & 35.43 & 2 & -0.40 & 0.0028 & RNA binding \\
\hline F1RZH4 & $\begin{array}{l}\text { Uncharacterized protein OS }=\text { Sus scrofa PE }=4 \mathrm{SV}=1 \\
\text { - [F1RZH4_PIG] }\end{array}$ & ADAM10 & 32.67 & 1 & -0.82 & 0.0048 & $\begin{array}{l}\text { Structural constituent of } \\
\text { ribosome }\end{array}$ \\
\hline F1SD98 & $\begin{array}{l}\text { Uncharacterized protein OS }=\text { Sus scrofa GN }=\text { TRMT1 } \\
\mathrm{PE}=4 \mathrm{SV}=2-\left[\mathrm{F} 1 \mathrm{SD} 98 \_\mathrm{PIG}\right]\end{array}$ & TRMT1 & 27.72 & 1 & -0.30 & 0.0065 & Poly(A) RNA binding \\
\hline I3LHZ6 & $\begin{array}{l}\text { Uncharacterized protein OS = Sus scrofa GN = DHX9 } \\
\mathrm{PE}=4 \mathrm{SV}=1-\left[13 \mathrm{LHZ6 \_ PIG]}\right.\end{array}$ & $\mathrm{DHX9}$ & 994.71 & 27 & -0.30 & 0.0075 & $\begin{array}{l}\text { ATP-dependent RNA helicase } \\
\text { activity }\end{array}$ \\
\hline F1SDV7 & $\begin{array}{l}\text { Uncharacterized protein (Fragment) OS }=\text { Sus scrofa } \\
\mathrm{GN}=\mathrm{TOP} 1 \mathrm{PE}=4 \mathrm{SV}=1-\text { [F1SDV7_PIG] }\end{array}$ & TOP1 & 99.93 & 4 & -0.44 & 0.0075 & DNA binding \\
\hline P62802 & Histone H4 OS = Sus scrofa PE = 1 SV = 2 - [H4_PIG] & None & 358.11 & 7 & -0.67 & 0.0103 & DNA binding \\
\hline F1S1V1 & $\begin{array}{l}\text { Uncharacterized protein OS }=\text { Sus scrofa GN }=\text { SSB PE } \\
=4 \mathrm{SV}=2-\left[\mathrm{F} 1 \mathrm{~S} 1 \mathrm{~V} 1 \_\mathrm{PIG}\right]\end{array}$ & SSB & 196.5 & 6 & -0.73 & 0.0111 & Nucleotide binding \\
\hline F1RS45 & $\begin{array}{l}\text { DNA topoisomerase } 2 \mathrm{OS}=\text { Sus scrofa PE }=3 \mathrm{SV}=2 \text { - } \\
\text { [F1RS45_PIG] }\end{array}$ & TOP2B & 116.62 & 6 & -0.27 & 0.0117 & DNA binding \\
\hline F1S1X3 & $\begin{array}{l}\text { Uncharacterized protein OS = Sus scrofa GN = NARS } \\
P E=3 S V=2-\left[F 1 S 1 X 3 \_P I G\right]\end{array}$ & NARS & 262.65 & 7 & -0.30 & 0.0119 & Nucleotide binding \\
\hline F2Z576 & $\begin{array}{l}\text { Histone H3 OS = Sus scrofa GN }=\text { LOC100525821 PE }= \\
2 \mathrm{SV}=1-\left[\mathrm{F} 2 \mathrm{Z} 576 \_P I G\right]\end{array}$ & HIST1H3E & 159.44 & 6 & -0.77 & 0.0120 & DNA binding \\
\hline Q29194 & $\begin{array}{l}\text { Ribosomal protein S2 (Fragment) OS = Sus scrofa PE = } \\
2 \mathrm{SV}=1 \text { - [Q29194_PIG] }\end{array}$ & None & 46.59 & 1 & -0.45 & 0.0138 & $\begin{array}{l}\text { Structural constituent of } \\
\text { ribosome }\end{array}$ \\
\hline I3LFV4 & $\begin{array}{l}\text { Uncharacterized protein OS = Sus scrofa } G N=\text { YBX1 } \\
\mathrm{PE}=4 \mathrm{SV}=1-[13 \mathrm{LFV} 4 \text { _PIG] }\end{array}$ & YBX1 & 157.89 & 4 & 0.41 & 0.0148 & DNA repair \\
\hline I3LIN8 & $\begin{array}{l}\text { Histone H2A OS }=\text { Sus scrofa GN }=\text { H2AFY PE }=3 \mathrm{SV}= \\
1-[\text { [ILIN8_PIG] }\end{array}$ & $\mathrm{H} 2 \mathrm{AFY}$ & 224.89 & 6 & -0.52 & 0.0149 & Chromatin DNA binding \\
\hline BOFWK5 & $\begin{array}{l}\text { Ribosomal protein } \mathrm{L} 5 \mathrm{OS}=\text { Sus scrofa } \mathrm{GN}=\mathrm{RPL} 5 \mathrm{PE}= \\
2 \mathrm{SV}=1-[\mathrm{BOFWK5} \mathrm{PIG}]\end{array}$ & RPL5 & 178.57 & 8 & -0.34 & 0.0165 & $\begin{array}{l}\text { Structural constituent of } \\
\text { ribosome }\end{array}$ \\
\hline $13 \mathrm{LCl} 4$ & $\begin{array}{l}\text { Uncharacterized protein OS = Sus scrofa GN = ZFR PE } \\
=4 \mathrm{SV}=1-[13 \mathrm{LCl} 4 \text { PIG] }\end{array}$ & ZFR & 41.93 & 2 & -0.28 & 0.0167 & Poly(A) RNA binding \\
\hline F1S8A5 & $\begin{array}{l}\text { Uncharacterized protein OS= Sus scrofa GN }=\text { MRPS26 } \\
\mathrm{PE}=4 \mathrm{SV}=1-[\mathrm{F} 1 \mathrm{~S} 8 \mathrm{~A} 5 \text { PIG] }\end{array}$ & MRPS26 & 38.63 & 1 & -0.36 & 0.0181 & Poly(A) RNA binding \\
\hline A5GFY4 & $\begin{array}{l}\text { Negative elongation factor D OS = Sus scrofa GN }= \\
\text { NELFCD PE }=3 \mathrm{SV}=1-[\mathrm{NELFD} P \mathrm{PIG}]\end{array}$ & NELFCD & 43.67 & 1 & -0.32 & 0.0189 & $\begin{array}{l}\text { Negative regulation of } \\
\text { transcription }\end{array}$ \\
\hline F1S5A8 & $\begin{array}{l}\text { Uncharacterized protein OS = Sus scrofa GN }=\mathrm{DHX} 15 \\
\mathrm{PE}=4 \mathrm{SV}=1-[\mathrm{F} 1 \mathrm{~S} 5 \mathrm{~A} 8 \text { _PIG] }\end{array}$ & DHX15 & 259.43 & 8 & -0.26 & 0.0198 & $\begin{array}{l}\text { ATP-dependent RNA helicase } \\
\text { activity }\end{array}$ \\
\hline F1RRG9 & $\begin{array}{l}\text { Uncharacterized protein OS = Sus scrofa GN = } \\
\text { SMARCA5 PE }=4 \mathrm{SV}=1-\text { [F1RRG9_PIG] }\end{array}$ & SMARCA5 & 99.44 & 3 & -0.39 & 0.0201 & DNA binding \\
\hline F1RGP1 & $\begin{array}{l}\text { Uncharacterized protein OS }=\text { Sus scrofa GN }= \\
\text { MYBBP1A PE }=4 \mathrm{SV}=1-[\mathrm{F} 1 \mathrm{RGP1} \text { PIG] }\end{array}$ & MYBBP1A & 445.89 & 12 & -0.50 & 0.0208 & Poly(A) RNA binding \\
\hline $\mathrm{F} 2 \mathrm{Z} 5 \mathrm{Q} 8$ & $\begin{array}{l}\text { Uncharacterized protein OS = Sus scrofa GN }= \\
\mathrm{LOC} 100519675 \mathrm{PE}=4 \mathrm{SV}=1-[\mathrm{F} 2 \mathrm{Z5Q8} \text { PPIG] }\end{array}$ & RPL35A & 57.33 & 2 & -0.45 & 0.0209 & $\begin{array}{l}\text { Structural constituent of } \\
\text { ribosome }\end{array}$ \\
\hline
\end{tabular}


Table 4 List of differentially expressed proteins in small intestinal mucosal samples from treatment group and control group (Continued)

\begin{tabular}{|c|c|c|c|c|c|c|c|}
\hline 13L7T6 & $\begin{array}{l}\text { Histone H2A OS = Sus scrofa GN }=\text { H2AFX PE }=3 \mathrm{SV}= \\
1-[13 \mathrm{LTT} 6 \text { PIG }]\end{array}$ & H2AFX & 357.7 & 7 & -0.56 & 0.0231 & DNA binding \\
\hline F1SMZ9 & $\begin{array}{l}\text { Uncharacterized protein (Fragment) OS }=\text { Sus scrofa } \\
\mathrm{GN}=\mathrm{SF} 3 \mathrm{~B} 1 \mathrm{PE}=4 \mathrm{SV}=2-\left[\mathrm{F} 1 \mathrm{SMZ9} \_\mathrm{PIG}\right]\end{array}$ & SF3B1 & 267.33 & 9 & -0.26 & 0.0245 & mRNA binding \\
\hline F2Z5K9 & $\begin{array}{l}\text { Histone H3 OS = Sus scrofa GN = LOC100622412 PE = } \\
3 \mathrm{SV}=1-\text { [F2Z5K9_PIG] }\end{array}$ & LOC100622412 & 178.75 & 6 & -0.76 & 0.0270 & DNA binding \\
\hline P53027 & $\begin{array}{l}\text { 60S ribosomal protein L10a (Fragment) OS = Sus } \\
\text { scrofa GN }=R P L 10 A P E=2 S V=3-\left[R L 10 A \_P I G\right]\end{array}$ & RPL10A & 154.25 & 5 & -0.34 & 0.0272 & RNA binding \\
\hline K9IVG8 & $\begin{array}{l}\text { DEAD (Asp-Glu-Ala-Asp) box helicase } 21 \text { OS = Sus } \\
\text { scrofa GN }=\text { DDX21 PE }=2 \mathrm{SV}=1-\text { [K9IVG8_PIG] }\end{array}$ & DDX21 & 44.62 & 1 & -0.38 & 0.0292 & RNA binding \\
\hline F2Z554 & $\begin{array}{l}\text { Uncharacterized protein OS = Sus scrofa GN = RPL30 } \\
\mathrm{PE}=3 \mathrm{SV}=1-\text { [F2Z554_PIG] }\end{array}$ & RPL30 & 105.87 & 4 & -0.26 & 0.0323 & RNA binding \\
\hline Q29195 & $\begin{array}{l}\text { 60S ribosomal protein } L 10 \text { OS }=\text { Sus scrofa } G N=\text { RPL10 } \\
P E=2 S V=3-\left[R L 10 \_P I G\right]\end{array}$ & RPL10 & 105.8 & 4 & -0.39 & 0.0350 & $\begin{array}{l}\text { Structural constituent of } \\
\text { ribosome }\end{array}$ \\
\hline P67985 & $\begin{array}{l}\text { 60S ribosomal protein } \mathrm{L} 22 \text { OS }=\text { Sus scrofa } G N=R P L 22 \\
P E=2 \mathrm{SV}=2-\left[\mathrm{RL} 22 \_\mathrm{PIG}\right]\end{array}$ & RPL22 & 113.83 & 3 & -0.48 & 0.0355 & $\begin{array}{l}\text { Structural constituent of } \\
\text { ribosome }\end{array}$ \\
\hline I7GF95 & $\begin{array}{l}\text { Guanine nucleotide binding protein-like } 1 \mathrm{OS}=\text { Sus } \\
\text { scrofa } \mathrm{GN}=\mathrm{GNL} 1 \mathrm{PE}=4 \mathrm{SV}=1-\text { [17GF95_PIG] }\end{array}$ & GNL1 & 58.56 & 1 & -0.35 & 0.0371 & Ribosome biogenesis \\
\hline F1S8L9 & $\begin{array}{l}\text { Uncharacterized protein OS = Sus scrofa GN = } \\
\text { HNRNPU PE }=4 \mathrm{SV}=2-[\mathrm{F} 1 \mathrm{~S} 8 \mathrm{~L} \text {.PIG] }\end{array}$ & HNRNPU & 883.61 & 23 & -0.34 & 0.0377 & Poly(A) RNA binding \\
\hline Q53DY5 & 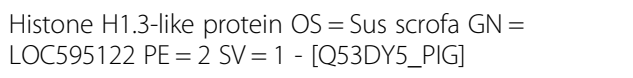 & HIST1H1D & 251.92 & 7 & 1.29 & 0.0384 & Chromatin DNA binding \\
\hline F1S2G3 & $\begin{array}{l}\text { Uncharacterized protein (Fragment) OS = Sus scrofa } \\
\text { GN }=\text { TBCA PE }=4 \mathrm{SV}=1-\text { [F1S2G3_PIG] }\end{array}$ & TBCA & 78.18 & 2 & 0.31 & 0.0389 & Poly(A) RNA binding \\
\hline F2Z5P1 & $\begin{array}{l}\text { Histone H2A (Fragment) OS = Sus scrofa GN = H2AFV } \\
\mathrm{PE}=3 \mathrm{SV}=1-\left[\mathrm{F} 2 \mathrm{Z} 5 \mathrm{P} 1 \_\mathrm{PIG}\right]\end{array}$ & LOC100512448 & 256.74 & 5 & -0.43 & 0.0427 & DNA binding \\
\hline F2Z553 & $\begin{array}{l}\text { Uncharacterized protein OS }=\text { Sus scrofa GN }=\text { EIF1 PE } \\
=4 \mathrm{SV}=1-\left[\mathrm{F} 2 \mathrm{Z} 553 \_\mathrm{PIG}\right]\end{array}$ & EIF1 & 103.66 & 2 & 0.82 & 0.0437 & $\begin{array}{l}\text { Translation initiation factor } \\
\text { activity }\end{array}$ \\
\hline F2Z5L5 & $\begin{array}{l}\text { Histone H2A OS = Sus scrofa GN }=\text { HIST2H2AC PE }=3 \\
\mathrm{SV}=1-\left[\mathrm{F} 2 Z 5 \mathrm{~L} 5 \_\mathrm{PIG}\right]\end{array}$ & $\mathrm{HIST} 2 \mathrm{H} 2 \mathrm{AC}$ & 322.1 & 5 & -0.62 & 0.0448 & DNA binding \\
\hline \multicolumn{8}{|c|}{ Redox homeostasis and detoxification } \\
\hline F1SKJ2 & $\begin{array}{l}\text { Uncharacterized protein OS = Sus scrofa GN }=\mathrm{TXN2} \\
\mathrm{PE}=4 \mathrm{SV}=1-\left[\mathrm{F} 1 \mathrm{SKJ} 2 \_\mathrm{PIG}\right]\end{array}$ & TXN2 & 29.86 & 1 & 0.39 & 0.0043 & Cell redox homeostasis \\
\hline F1SGS9 & $\begin{array}{l}\text { Catalase OS }=\text { Sus scrofa GN }=\text { CAT PE }=3 \mathrm{SV}=1 \text { - } \\
\text { [F1SGS9_PIG] }\end{array}$ & CAT & 923.56 & 23 & 0.58 & 0.0151 & $\begin{array}{l}\text { Protect cells from the toxic } \\
\text { effects of hydrogen peroxide }\end{array}$ \\
\hline 13LDJ8 & $\begin{array}{l}\text { Uncharacterized protein OS }=\text { Sus scrofa PE }=3 \mathrm{SV}=1 \\
\text { - [I3LDJ8_PIG] }\end{array}$ & None & 303.51 & 10 & 0.77 & 0.0202 & Oxidoreductase activity \\
\hline P12309 & $\begin{array}{l}\text { Glutaredoxin-1 OS = Sus scrofa GN }=\text { GLRX PE }=1 \mathrm{SV}= \\
2 \text { - [GLRX1_PIG] }\end{array}$ & GLRX & 277.83 & 6 & 0.64 & 0.0208 & Cell redox homeostasis \\
\hline F1SCF9 & $\begin{array}{l}\text { Uncharacterized protein (Fragment) OS = Sus scrofa } \\
\text { GN }=\text { TECR PE }=4 \mathrm{SV}=2-[\text { [F1SCF9_PIG] }\end{array}$ & TECR & 38.34 & 1 & -0.37 & 0.0242 & Oxidoreductase activity \\
\hline A5J2A8 & $\begin{array}{l}\text { Thioredoxin (Fragment) OS = Sus scrofa GN }=\text { TRX PE } \\
=4 \mathrm{SV}=1-\left[\mathrm{A} 5 \mathrm{~J} 2 \mathrm{~A} 8 \_\mathrm{PIG}\right]\end{array}$ & TRX & 128.36 & 3 & 0.34 & 0.0303 & Cell redox homeostasis \\
\hline F1SMY1 & $\begin{array}{l}\text { Uncharacterized protein OS = Sus scrofa GN }=\mathrm{TMX} 3 \\
\mathrm{PE}=4 \mathrm{SV}=2-\text { [F1SMY1_PIG] }\end{array}$ & TMX3 & 39.1 & 2 & 0.30 & 0.0345 & Cell redox homeostasis \\
\hline P16549 & $\begin{array}{l}\text { Dimethylaniline monooxygenase [N-oxide-forming] } 1 \\
\text { OS }=\text { SuS scrofa GN =FMO1 PE }=1 \mathrm{SV}=3 \text { - } \\
\text { [FMO1_PIG] }\end{array}$ & FMO1 & 39.55 & 2 & 1.64 & 0.0084 & $\begin{array}{l}\text { Oxidative metabolism of a } \\
\text { variety of xenobiotics }\end{array}$ \\
\hline P04178 & $\begin{array}{l}\text { Superoxide dismutase [Cu-Zn] OS = Sus scrofa GN = } \\
\text { SOD1 PE }=1 \mathrm{SV}=2-\left[\mathrm{SODC} \_\mathrm{PIG}\right]\end{array}$ & SOD1 & 459.04 & 9 & 0.35 & 0.0424 & $\begin{array}{l}\text { Superoxide dismutase } \\
\text { activity }\end{array}$ \\
\hline \multicolumn{8}{|c|}{ Immune response and inflammation } \\
\hline A3FJ41 & $\begin{array}{l}\text { MHC class I antigen (Fragment) OS = Sus scrofa GN }= \\
\text { SLA-1 PE }=4 \mathrm{SV}=1-[\text { [A3FJ41_PIG] }\end{array}$ & SLA-1 & 120.03 & 5 & 0.35 & 0.0050 & Immune response \\
\hline
\end{tabular}


Table 4 List of differentially expressed proteins in small intestinal mucosal samples from treatment group and control group (Continued)

\begin{tabular}{|c|c|c|c|c|c|c|c|}
\hline F1RGC8 & $\begin{array}{l}\text { Uncharacterized protein OS = Sus scrofa GN = NLRP6 } \\
\mathrm{PE}=4 \mathrm{SV}=3-\text { [F1RGC8_PIG] }\end{array}$ & NLRP6 & 119.58 & 4 & -0.32 & 0.0061 & Activation of NF-KB \\
\hline F1RFM7 & $\begin{array}{l}\text { Uncharacterized protein OS = Sus scrofa GN = AIMP2 } \\
\mathrm{PE}=4 \mathrm{SV}=1 \text { - [F1RFM7_PIG] }\end{array}$ & AIMP2 & 232.75 & 6 & -0.29 & 0.0076 & Metabolism of xenobiotics \\
\hline A2SZV5 & $\begin{array}{l}\text { Tax1 binding protein } 3 \text { (Fragment) OS = Sus scrofa PE } \\
=4 \mathrm{SV}=1-\left[\mathrm{A} 2 \mathrm{SZV} 5 \_P I G\right]\end{array}$ & None & 55.14 & 1 & 0.29 & 0.0133 & Negative regulation of $\mathrm{NF}-\mathrm{kB}$ \\
\hline B8XX91 & $\begin{array}{l}\text { DNA-dependent activator of IFN-regulatory factor OS } \\
=\text { Sus scrofa GN }=\text { DAI PE }=2 \mathrm{SV}=1-[\mathrm{B} 8 \mathrm{XX91} \mathrm{PIG}]\end{array}$ & DAl & 100.5 & 4 & 0.70 & 0.0137 & Innate immune responses \\
\hline Q8WNQ7 & $\begin{array}{l}\text { N-acetylgalactosamine-6-sulfatase OS }=\text { Sus scrofa GN } \\
=\text { GALNS PE }=2 \mathrm{SV}=1-[\mathrm{GALNS} \text { PIG] }\end{array}$ & GALNS & 52.52 & 1 & 0.60 & 0.0311 & $\begin{array}{l}\text { Degradation of the } \\
\text { glycosaminoglycans keratan } \\
\text { sulfate }\end{array}$ \\
\hline B8XTR8 & $\begin{array}{l}\text { Granzyme H OS = Sus scrofa GN }=\text { gzmH PE }=2 \mathrm{SV}=1 \\
\text { - [B8XTR8_PIG] }\end{array}$ & gzmH & 168.84 & 6 & -0.67 & 0.0272 & $\begin{array}{l}\text { Serine-type endopeptidase } \\
\text { activity }\end{array}$ \\
\hline A5GFQ5 & $\begin{array}{l}\text { Protein canopy homolog } 3 \mathrm{OS}=\text { Sus scrofa GN }= \\
\text { CNPY3 PE }=3 \mathrm{SV}=1-[\text { CNPY3_PIG] }\end{array}$ & CNPY3 & 40.13 & 2 & -0.63 & 0.0376 & $\begin{array}{l}\text { Receptor binding for proper } \\
\text { TLR folding }\end{array}$ \\
\hline \multicolumn{8}{|c|}{ Energy metabolism } \\
\hline Q1ACV5 & $\begin{array}{l}\text { Transporter associated with antigen processing } 1 \mathrm{OS} \\
=\text { Sus scrofa } \mathrm{PE}=2 \mathrm{SV}=1-\left[\mathrm{Q} 1 \mathrm{ACV} 5 \_\mathrm{PIG}\right]\end{array}$ & None & 298.67 & 7 & -0.32 & 0.0030 & Triggers ATP hydrolysis \\
\hline F1RIG0 & $\begin{array}{l}\text { Uncharacterized protein (Fragment) OS = Sus scrofa } \\
\mathrm{PE}=4 \mathrm{SV}=1 \text { - [F1RIGO_PIG] }\end{array}$ & None & 47.28 & 2 & -0.27 & 0.0169 & ATP binding \\
\hline Q7SIB7 & $\begin{array}{l}\text { Phosphoglycerate kinase } 1 \mathrm{OS}=\text { Sus scrofa GN }=\text { PGK1 } \\
\mathrm{PE}=1 \mathrm{SV}=3-\left[\mathrm{PGK}{ }_{-} \mathrm{PIG}\right]\end{array}$ & PGK1 & 850.39 & 23 & 0.30 & 0.0160 & $\begin{array}{l}\text { Conversion of 1,3- } \\
\text { diphosphoglycerate to 3- } \\
\text { phosphoglycerate }\end{array}$ \\
\hline H9BYW2 & $\begin{array}{l}\text { Acyl-coenzyme A oxidase OS }=\text { Sus scrofa } G N= \\
\text { ACOX1 } P E=2 S V=1-\left[H 9 B Y W 2 \_P I G\right]\end{array}$ & ACOX1 & 370.35 & 10 & 0.91 & 0.0200 & Fatty acid beta-oxidation \\
\hline I3LEN7 & $\begin{array}{l}\text { Uncharacterized protein OS = Sus scrofa GN = } \\
\text { ALDH1L1 PE }=3 \mathrm{SV}=1-\text { [I3LEN7_PIG] }\end{array}$ & ALDH1L1 & 49.04 & 2 & 0.40 & 0.0245 & Formate oxidation \\
\hline F1SOY8 & $\begin{array}{l}\text { Uncharacterized protein OS = Sus scrofa } \mathrm{GN}=\mathrm{ADH} 4 \\
\mathrm{PE}=3 \mathrm{SV}=2-[\mathrm{F} 1 \mathrm{SOY} 8 \mathrm{PIG}]\end{array}$ & $\mathrm{ADH} 4$ & 40.7 & 2 & 0.67 & 0.0309 & $\begin{array}{l}\text { Oxidation of long-chain ali- } \\
\text { phatic alcohols }\end{array}$ \\
\hline A7UIU7 & $\begin{array}{l}\text { ATP citrate lyase OS = Sus scrofa GN }=\mathrm{ACL} P \mathrm{PE}=2 \mathrm{SV} \\
=1-[\text { A7UIU7_PIG] }\end{array}$ & $\mathrm{ACL}$ & 468.98 & 14 & -0.38 & 0.0374 & ATP binding \\
\hline \multicolumn{8}{|c|}{ Protein metabolism and modification } \\
\hline F1RIF3 & $\begin{array}{l}\text { Uncharacterized protein OS = Sus scrofa GN }=\text { FAH PE } \\
=4 \mathrm{SV}=1 \text { - [F1RIF3_PIG] }\end{array}$ & $\mathrm{FAH}$ & 38.37 & 2 & 0.39 & 0.0010 & $\begin{array}{l}\text { Catabolism of the amino } \\
\text { acid phenylalanine }\end{array}$ \\
\hline Q9GK25 & $\begin{array}{l}\text { Peptidyl-prolyl cis-trans isomerase (Fragment) OS = } \\
\text { Sus scrofa PE }=2 \mathrm{SV}=1-[\mathrm{Q} 9 \mathrm{GK} 25 \text { PIG] }\end{array}$ & None & 266.1 & 7 & 1.43 & 0.0025 & $\begin{array}{l}\text { Accelerate the folding of } \\
\text { proteins }\end{array}$ \\
\hline |3L739 & $\begin{array}{l}\text { Uncharacterized protein OS = Sus scrofa GN = JMJD6 } \\
P E=4 \mathrm{SV}=1-\left[13 \mathrm{~L} 739 \_P I G\right]\end{array}$ & JMJD6 & 39.99 & 1 & -0.29 & 0.0193 & Protein hydroxylases \\
\hline I3LK37 & $\begin{array}{l}\text { Uncharacterized protein (Fragment) OS = Sus scrofa } \\
\mathrm{PE}=3 \mathrm{SV}=1-[13 \mathrm{LK37} \mathrm{PIG}]\end{array}$ & GALNT7 & 33.39 & 2 & -0.30 & 0.0248 & Protein glycosylation \\
\hline F1RNR6 & $\begin{array}{l}\text { 4-hydroxyphenylpyruvate dioxygenase OS = Sus scrofa } \\
\mathrm{GN}=\mathrm{HPD} P E=3 \mathrm{SV}=2 \text { - [F1RNR6_PIG] }\end{array}$ & HPD & 31 & 1 & 0.35 & 0.0391 & $\begin{array}{l}\text { Aromatic amino acid family } \\
\text { metabolic process }\end{array}$ \\
\hline \multicolumn{8}{|c|}{ Lipid metabolism } \\
\hline I3LM15 & $\begin{array}{l}\text { Uncharacterized protein OS= Sus scrofa GN = AGPS } \\
\mathrm{PE}=4 \mathrm{SV}=1-\left[\mathrm{I} L \mathrm{LM} 15 \_\mathrm{PIG}\right]\end{array}$ & AGPS & 48.77 & 1 & -0.36 & 0.0019 & Lipid biosynthetic process \\
\hline Q9GJX2 & $\begin{array}{l}\text { Diazepam binding inhibitor (Fragment) OS = Sus } \\
\text { scrofa } G N=D B I P E=2 S V=1-\left[Q 9 G J X 2 \_P I G\right]\end{array}$ & $\mathrm{DBI}$ & 80.13 & 3 & 0.91 & 0.0057 & $\begin{array}{l}\text { Long-chain fatty acyl-CoA } \\
\text { binding, triglyceride meta- } \\
\text { bolic process }\end{array}$ \\
\hline P27917 & $\begin{array}{l}\text { Apolipoprotein C-III OS = Sus scrofa GN = APOC3 PE }= \\
1 \mathrm{SV}=2-[\mathrm{APOC} 3 \mathrm{PIG}]\end{array}$ & APOC3 & 226.39 & 7 & 0.78 & 0.0241 & $\begin{array}{l}\text { High-density lipoprotein } \\
\text { particle receptor binding }\end{array}$ \\
\hline \multicolumn{8}{|c|}{ Cell cytoskeleton } \\
\hline P10668 & $\begin{array}{l}\text { Cofilin-1 OS = Sus scrofa GN =CFL1 PE = } 1 \text { SV = } 3 \text { - } \\
\text { [COF1_PIG] }\end{array}$ & CFL1 & 704.02 & 15 & 0.31 & 0.0059 & Cytoskeleton organization \\
\hline
\end{tabular}


Table 4 List of differentially expressed proteins in small intestinal mucosal samples from treatment group and control group (Continued)

\begin{tabular}{|c|c|c|c|c|c|c|c|}
\hline Q5G6W0 & $\begin{array}{l}\text { Cofilin-2 (Fragment) OS = Sus scrofa PE = 2 SV = } 1 \text { - } \\
\text { [Q5G6W0_PIG] }\end{array}$ & CFL1 & 48.67 & 2 & 0.43 & 0.0073 & Cytoskeleton organization \\
\hline B5APV0 & $\begin{array}{l}\text { Actin-related protein 2/3 complex subunit } 5 \mathrm{OS}=\text { Sus } \\
\text { scrofa } \mathrm{GN}=\mathrm{ARPC5} \mathrm{PE}=2 \mathrm{SV}=1-[\mathrm{B} 5 \mathrm{APV} 0 \text { PIG }]\end{array}$ & ARPC5 & 170.99 & 6 & 0.30 & 0.0167 & $\begin{array}{l}\text { Structural constituent of } \\
\text { cytoskeleton }\end{array}$ \\
\hline \multicolumn{8}{|c|}{ Miscellaneous } \\
\hline Q9TSA7 & $\begin{array}{l}\text { Calmodulin (Fragments) OS = Sus scrofa PE }=4 \text { SV }=1 \\
\text { - [Q9TSA7_PIG] }\end{array}$ & None & 108.72 & 4 & 1.11 & 0.0008 & Calcium ion binding \\
\hline K7GKQ1 & $\begin{array}{l}\text { Uncharacterized protein OS = Sus scrofa } G N=\text { RAB9A } \\
P E=3 S V=1-\left[K 7 G K Q 1 \_P I G\right]\end{array}$ & RAB9A & 26.6 & 1 & -0.40 & 0.0071 & Cytoskeletal signaling \\
\hline F1RKI3 & $\begin{array}{l}\text { Uncharacterized protein OS = Sus scrofa GN = HINT1 } \\
\mathrm{PE}=4 \mathrm{SV}=1-\text { [F1RKI3_PIG] }\end{array}$ & HINT1 & 80.55 & 3 & 0.32 & 0.0073 & Tumor suppressing \\
\hline I3LSYO & $\begin{array}{l}\text { Uncharacterized protein OS = Sus scrofa GN = ACSM4 } \\
\mathrm{PE}=4 \mathrm{SV}=1-[13 \mathrm{LSYO} \mathrm{PIG}]\end{array}$ & ACSM4 & 21.13 & 1 & 0.86 & 0.0179 & Catalytic activity \\
\hline D0G6R8 & $\begin{array}{l}\text { Phosphatidate cytidylyltransferase OS = Sus scrofa GN } \\
=\mathrm{CDS} 2 \mathrm{PE}=2 \mathrm{SV}=1-\left[\mathrm{D} 0 \mathrm{G} 6 \mathrm{R} 8 \_\mathrm{PIG}\right]\end{array}$ & CDS2 & 33.01 & 1 & -0.39 & 0.0192 & $\begin{array}{l}\text { Synthesis of } \\
\text { phosphatidylglycerol }\end{array}$ \\
\hline Q95332 & $\begin{array}{l}\text { Betaine-homocysteine S-methyltransferase } 1 \text { (Frag- } \\
\text { ment) OS = Sus scrofa GN = BHMT PE = } 1 \mathrm{SV}=3 \text { - } \\
\text { [BHMT1_PIG] }\end{array}$ & BHMT & 110.41 & 4 & 1.10 & 0.0193 & $\begin{array}{l}\text { Regulation of homocysteine } \\
\text { metabolism }\end{array}$ \\
\hline F1RS34 & $\begin{array}{l}\text { Uncharacterized protein OS = Sus scrofa GN = GAPVD1 } \\
\mathrm{PE}=4 \mathrm{SV}=2-\text { [F1RS34_PIG] }\end{array}$ & GAPVD1 & 22.69 & 1 & -0.40 & 0.0207 & Signal transduction \\
\hline F1ST01 & $\begin{array}{l}\text { Uncharacterized protein OS=Sus scrofa GN }= \\
\text { SELENBP1 PE }=4 \mathrm{SV}=1 \text { - [F1ST01_PIG] }\end{array}$ & SELENBP1 & 936.42 & 22 & 0.33 & 0.0209 & Selenium binding \\
\hline Q9TV62 & $\begin{array}{l}\text { Myosin-4 OS = Sus scrofa GN = MYH4 PE = 2 SV = } 1- \\
\text { [MYH4_PIG] }\end{array}$ & $\mathrm{MYH} 4$ & 192.94 & 7 & -0.83 & 0.0336 & Motor activity \\
\hline F1RN91 & $\begin{array}{l}\text { Uncharacterized protein (Fragment) OS = Sus scrofa } \\
\mathrm{PE}=4 \mathrm{SV}=2-[\text { F1RN91_PIG] }\end{array}$ & MYO18A & 35.04 & 2 & 0.28 & 0.0355 & Cell migration \\
\hline F1RPC8 & $\begin{array}{l}\text { Uncharacterized protein OS = Sus scrofa GN =CRYM } \\
\mathrm{PE}=4 \mathrm{SV}=2-[\mathrm{F} 1 \mathrm{RPC} 8 \mathrm{PIG}]\end{array}$ & CRYM & 59.33 & 2 & 0.49 & 0.0392 & Thyroid hormone binding \\
\hline F2Z5W6 & $\begin{array}{l}\text { Uncharacterized protein OS = Sus scrofa GN = } \\
\text { LAMTOR1 PE }=4 \mathrm{SV}=1-[\text { [F2Z5W6_PIG] }\end{array}$ & LAMTOR1 & 26.54 & 1 & -0.37 & 0.0410 & $\begin{array}{l}\text { Guanyl-nucleotide exchange } \\
\text { factor activity }\end{array}$ \\
\hline Q29069 & $\begin{array}{l}\text { Myosin light chain OS = Sus scrofa PE = 2 SV = 2 - } \\
\text { [Q29069_PIG] }\end{array}$ & None & 58.61 & 3 & -0.38 & 0.0458 & Calcium ion binding \\
\hline O19175 & $\begin{array}{l}\text { Casein kinase I isoform alpha (Fragment) OS = Sus } \\
\text { scrofa GN }=\text { CSNK1A1 PE }=2 \mathrm{SV}=1-\left[\mathrm{KC} 1 \mathrm{~A} \_\mathrm{PIG}\right]\end{array}$ & CSNK1A1 & 51.13 & 1 & -0.44 & 0.0473 & Protein kinase activity \\
\hline N0E654 & $\begin{array}{l}\text { Casein kinase II b subunit splicing isoform } 476 \\
\text { (Fragment) OS }=\text { Sus scrofa GN }=\text { Csnk2b PE }=2 \mathrm{SV}=1 \\
\text { - [NOE654_PIG] }\end{array}$ & Csnk2b & 63.97 & 2 & -0.27 & 0.0039 & $\begin{array}{l}\text { Cell proliferation and cell } \\
\text { differentiation }\end{array}$ \\
\hline
\end{tabular}

aniprot_Sus scrofa_9823 database accession number

${ }^{\mathrm{b}}$ The name of the protein exclusive of the identifier that appears in the database

'The sum of the scores of the individual peptides

${ }^{\mathrm{d}}$ The number of distinct peptide sequences in the protein group

eDifferential protein expression in the treatment group was presented as a $\log _{2}$ fold change relative to the control group

related to nutrient metabolism, transcriptional and translational regulation, immune, and redox homeostasis were identified in response to NSPEs.

In former research, the utilization of $\beta$-glucanase and xylanase in the diet demonstrated that enzymes tended to increase the absorptive area and reduce cell proliferation and intraepithelial lymphocytes in the gut of pigs [34]. Both cereal grains and enzymes would affect components of gut health, including intestine morphology, bacteria populations, and microbial metabolites in the gut content [35]. It has been demonstrated that enhanced cell proliferation in the intestinal mucosa is associated with bowel diseases, cellular repair, and apoptosis [36, 37]. As shown in the present study, $89 \%$ of proteins related to transcriptional and translational regulation were down-regulated in NSPE pigs. We speculate that supplementation with NSPEs in the diet of growing pigs can reduce the possibility of intestinal infection. This is consistent with the former research result that NSPEs reduce the amount of pathological bacteria within the small intestine by lowering the viscosity of intestinal digesta [11].

The abundance of proteins CFL1 (cofilin-1), CFL2 (cofilin-2) and ARPC5 (actin-related protein 2/3 complex subunit 5), which are classified as cell cytoskeleton 


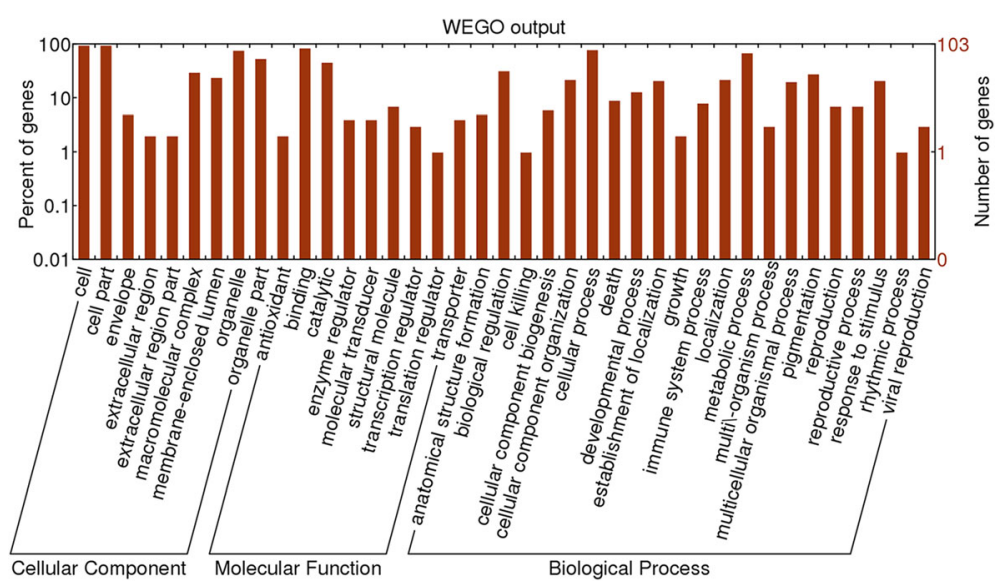

Fig. $2 \mathrm{GO}$ distribution analysis of differentially expressed proteins in small intestinal mucosal samples from the NSPE group and control group. The right coordinate axis indicates the number of proteins for each $\mathrm{GO}$ annotation, and the left one represents the proportion of proteins for every GO annotation

proteins relevant to cell structure and mobility, was increased. CFL1 and CFL2 are widely distributed intracellular actin-modulating proteins [38]. These two proteins can cause actin cytoskeleton rearrangement and membrane remodeling to the formation of phagosomes, which are recognized by Fc gamma receptors and beneficial for the host-defense in animals [39]. ARPC5 has a similar function as cofilin in the actin cytoskeleton, which is required for phagocytosis in mammals [40]. The up-regulation of these proteins might reflect the improved integrity of the intestinal mucosa.

As an important immune organ, the small intestine participates in the inflammatory response and the prevention of bacterial infection. SLA-1 (MHC class I antigen), GALNS (N-acetylgalactosamine-6-sulfatase), and DAI
(DNA-dependent activator of IFN-regulatory factor) are considered to be involved in the immune response. SLA-1 alerts the immune system to virus-infected cells by presenting peptide fragments derived from intracellular proteins [41]. GALNS is located in lysosomes that digest different types of molecules and engulf viruses or bacteria within cells $[42,43]$. DAI selectively enhances the DNAmediated induction of type I IFN and other genes involved in innate immunity $[44,45]$. The abundance of these proteins was up-regulated in NSPE pigs, suggesting that the supplementation of NSPEs may improve potential immunity and reduce the chance of bacterial infection in the small intestine. This is consistent with the elevated serum level of IgG in the NSPE group. However, challenges with exogenous pathogens are still required to verify the effect

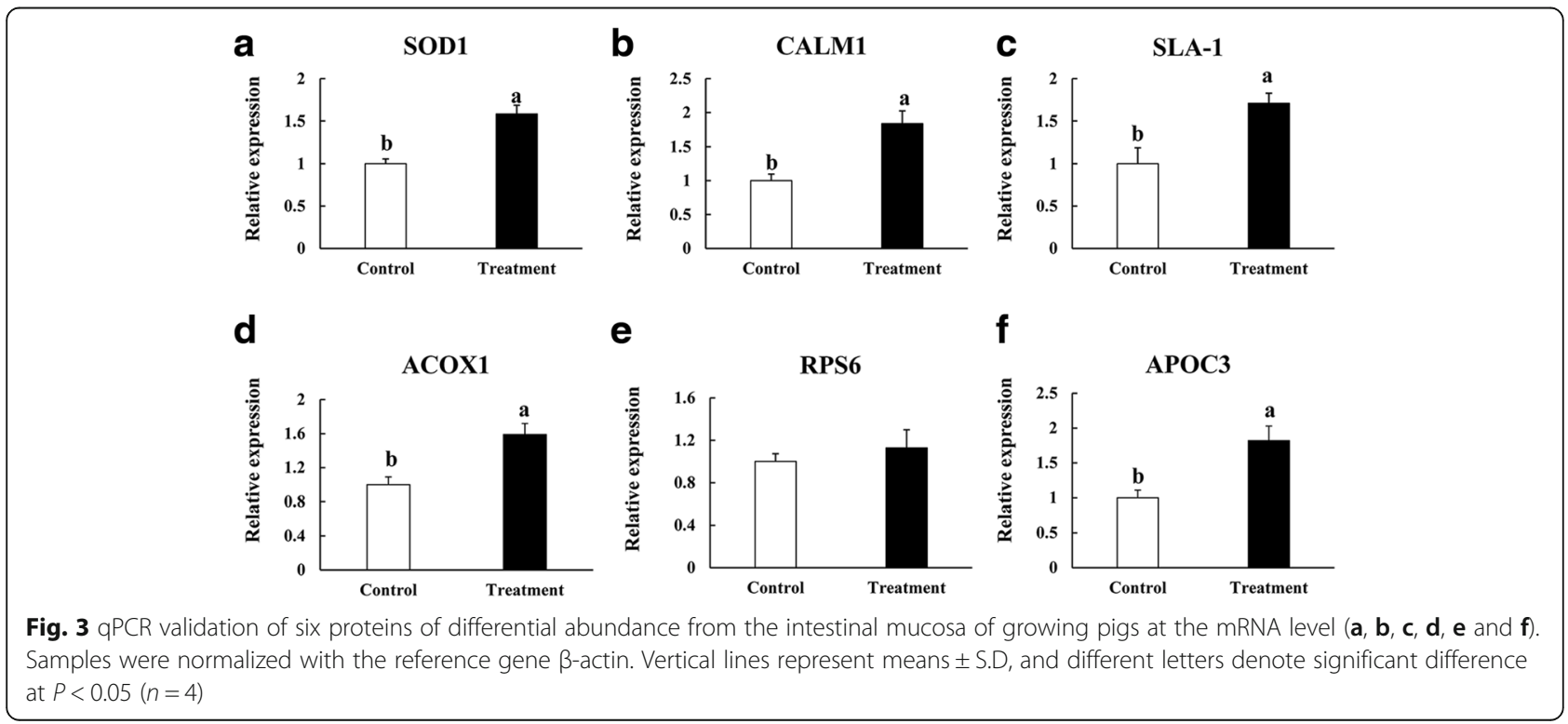


of NSPEs supplementation on immunity. In contrast, proteins involved in an inflammatory response, including NLRP6 (NLR family, pyrin domain containing 6) and CNPY3 (protein canopy homolog 3), are down-regulated, which indicates that inflammation is attenuated in the small intestinal mucosa due to the supplementation of NSPEs [46]. It has been suggested that one of the performance improvement attributes of NSPEs is due to the reduced local inflammation by controlling pathogens within the small intestine [32].

In addition to affecting the immune response, the upregulated proteins catalase (CAT), glutaredoxin (GRXS), thioredoxin (TRX), superoxide dismutase (SOD), dimethylaniline monooxygenase [N-oxide-forming] 1 (FMO1) and 4-hydroxyphenylpyruvate dioxygenase (HPPD) are classified as redox homeostasis and detoxification proteins based on their primary functions. The up-regulation of CAT, GRXS, TRX and SOD may suggest that NSPE pigs had more potential to keep redox homeostasis in vivo [47-52]. This is consistent with the increased serum level of T-SOD in the NSPE group of this study. The reason for the upregulation of these oxidoreductases and immune factors in the present study may be the increased abundance of reactive oxygen species (ROS) and inflammatory factors during stimulating energy metabolism due to a higher uptake of nutrients with NSPEs supplementation. However, further study is required to prove the effect of NSPEs on redox homeostasis. As one of the detoxification enzymes, FMO1 is regulated by xenobiotics, as the enzyme activity markedly increases in response to the invading harmful chemicals [53]. The up-regulation of this protein suggests that the supplementation of NSPEs is helpful to eliminate xenobiotics in the small intestine, which also could be related to the improvement of the intestinal lumen due to NSPEs.

Furthermore, the up-regulated abundance of proteins was observed in the NSPE group, including multiple nutrient metabolism processes such as energy, lipid, amino acid and mineral. These proteins included phosphoglycerate kinase 1 (PGK1), diazepam binding inhibitor (DBI), and acyl-coenzyme A oxidase (ACOX1). PGK1 plays a vital role in glycolysis or gluconeogenesis [54]. The up-regulation of ACOX1 indicates the elevation of glucose synthesis in the small intestine, which is consistent with the increased serum glucose level in the NSPE group. Likewise, higher abundance of DBI and ACOX1 was observed in this study, suggesting the stimulation of lipids $\beta$-oxidation for nutrient absorption to meet the energy requirement in the small intestine of NSPE pigs $[55,56]$. Apolipoprotein C-III (APOC3) is an important modulator that is secreted from the intestine on the chylomicron upon lipid absorption [57]. The up-regulation of APOC3 implies the enhanced absorption of dietary lipids in the NSPE group.

Two differentially expressed proteins related to the permeability of the tight junction (TJ), including casein kinase II beta subunit splicing isoform 476 (Csnk2b) and myosin-4 (MYH4), were identified in the present study. The tight junctions (TJs) in the small intestine are not only a physical and biological barrier but also a passive diffusion system that depends on the permeability of the TJs [58]. Paracellular transport is one of the passive diffusion systems providing an absorption way for small molecular compounds [59], which are regulated by the permeability of the TJs and are thought to be important for mineral absorption [60]. Additionally, the transepithelial transport of oligosaccharides, but not polysaccharides, also occurs via the paracellular pathway [61]. Previous research has demonstrated that NSPEs are capable of hydrolyzing polysaccharides from the food to oligosaccharides in the gut [62]. Thus, the down-regulation of these two proteins in this study, in addition to former studies, indicates an increased permeability of the TJs in the NSPE group, which is beneficial to small molecular compounds absorption in the small intestine.

Calmodulin regulates cellular calcium concentration as a primary calcium-binding protein [63]. Calcium absorption is reduced if the bioavailability of dietary calcium is lowered by calcium-binding agents like cellulose because nearly all dietary calcium intake occurs in the upper intestine [64]. The up-regulation of this protein observed in this study suggests that calcium absorption in the small intestine is facilitated in the NSPE group by the degradation of calcium-binding agents in the diet, which could be conductive to bone health.

It has been demonstrated that one of the important roles of NSPEs within the small intestine is the elimination of the nutrient-encapsulating effect of cell wall polysaccharides, which increases the availability of starches, amino acids, and minerals. These results are consistent with our results from the present study that the levels of proteins related to nutrient absorption and utilization (energy, lipid, amino acid and mineral) are up-regulated. A fully understanding of the mechanisms of NSPEs supplementation will require the determination of protein modifications and protein regulation such as phosphorylation or glycosylation [65]. However, this part was not involved in the present study due to the technical limitation. Thus, further study is required to prove the effect of NSPEs on regulatory proteins using specific method, for example, the phosphoproteome.

\section{Conclusions}

The results of this study provide the first evidence that the small intestinal mucosa proteome is altered in growing pigs supplemented with NSPEs. Growing pigs most likely responded to the increased reactive oxygen species (ROS) and inflammatory factors during stimulating energy metabolism due to NSPEs supplementation by changing the abundance of certain mucosal proteins that modulate 
redox homeostasis and enhance immune response. Most important of all, the effect of NSPEs on the increase of nutrient availability in the intestinal lumen provided additional benefits to facilitate protein expressions related to the efficiency of nutrient absorption and utilization, such as energy metabolism, amino acid metabolism, mineral metabolism, lipid absorption, and cell structure and mobility. These novel findings show the mechanisms whereby dietary supplementation with NSPEs promotes growth performance and improves the GI health of growing pigs, which also has important implications for the better utilization of this feed additive.

\section{Additional files}

Additional file 1: The detailed description of the experiment methods, including mass spectrometric analysis procedures and parameters, bioinformatics analysis softwares, websites and real-time $\mathrm{QPCR}$ procedures. (DOCX $15 \mathrm{~kb}$ )

Additional file 2: Table S1. qPCR primers used for verification of the differentially expressed genes of the small intestinal mucosa in growing pigs. (DOCX $14 \mathrm{~kb}$ )

Additional file 3: Table S2. List of all proteins $(n=2634)$ identified in the study. (XLSX $199 \mathrm{~kb}$ )

Additional file 4: Table S3. List of all differentially expressed proteins $(n=104)$ identified in the study. (XLSX $31 \mathrm{~kb})$

\section{Abbreviations}

ACOX1: Acyl-coenzyme A oxidase; ADFI: Average daily feed intake; ADG: Average daily gain; ALP: Alkaline phosphatase; ALT: Alanine aminotransferase; APOC3: Apolipoprotein C-III; ARPC5: Actin-related protein 2/3 complex subunit 5; AST: Aspartate aminotransferase; CALM1: Calmodulin; CAT: Catalase; CFL: Cofilin; CK: Creatine kinase; CNPY3: Protein canopy homolog 3; Csnk2b: Casein kinase II beta subunit splicing isoform 476 MYH4: myosin-4; DAl: DNA-dependent activator of IFN-regulatory factor; DTT: Dithiothreitol; FCR: Feed conversion ratio; FMO1: Dimethylaniline monooxygenase [N-oxide-forming] 1; GALNS: N-acetylgalactosamine-6sulfatase; GI: Gastrointestinal; GRXS: Glutaredoxin; HEPES: 4-(2-hydroxyethyl)1-piperazineethanesulfonic acid; HPPD: 4-hydroxyphenylpyruvate dioxygenase; IgG: Immunoglobulin G; iTRAQ: Isobaric tags for relative and absolute quantitation; NSPEs: Non-starch polysaccharide enzymes; PGK1: Phosphoglycerate kinase 1; PMSF: Phenylmethanesulfonyl fluoride; RPS6: 40S ribosomal protein S6; SLA-1: MHC class I antigen;

SOD1: Superoxide dismutase; TP: Total protein; TRX: Thioredoxin; T-SOD: Total superoxide dismutase

\section{Acknowledgements}

This research was supported by the Chinese National Science and Technology Pillar Program (No: 2012BAD39B0), the Special Fund for Innovation Team of the Chinese Academy of Agricultural Sciences (No: ASTTP-IAS07), and the Chinese National Key Basic Research and Development Program (No: 2014CB138804).

\section{Funding}

This research was supported by the Chinese National Science and Technology Pillar Program (No: 2012BAD39B0), the Special Fund for Innovation Team of the Chinese Academy of Agricultural Sciences (No: ASTTP-IAS07), and the Chinese National Key Basic Research and Development Program (No: 2014CB138804). The funders had no role in study design, data collection and analysis, decision to publish, or preparation of the manuscript.

Availability of data and materials

All relevant data are within the paper and its Additional files.

\section{Authors' contributions}

$\mathrm{JZ}$ and $\mathrm{HZ}$ designed the study. JZ and YG performed the experiments and analyzed the data. JZ, QL and RS contributed reagents/materials/analysis tools. JZ prepared the manuscript and all of the authors contributed to, read and approved the final manuscript.

\section{Competing interest}

The authors declare that there is no competing interest.

\section{Consent for publication}

Not applicable.

\section{Ethics approval}

This study was conducted in strict accordance with the Regulations for the Administration of Affairs Concerning Experimental Animals of the State Council of the People's Republic of China. The protocol was approved by the Committee on Experimental Animal Management of the Chinese Academy of Agricultural Sciences.

\section{Author details}

'Institute of Grassland Research, Chinese Academy of Agricultural Sciences, Hohhot 010010, People's Republic of China. ${ }^{2}$ State Key Laboratory of Animal Nutrition, Institute of Animal Sciences, Chinese Academy of Agricultural Sciences, Beijing 100193, People's Republic of China. ${ }^{3}$ College of Animal Science and Technology, Jilin Agricultural University, Changchun 130118, People's Republic of China.

Received: 4 June 2016 Accepted: 20 December 2016

Published online: 10 January 2017

\section{References}

1. Sterk A, Verdonk JMAJ, Mul AJ, Soenen B, Bezençon ML, Frehner M, et al. Effect of xylanase supplementation to a cereal-based diet on the apparent faecal digestibility in weanling piglets. Livest Sci. 2007;108(1-3):269-71.

2. Wang MQ, Xu ZR, Sun JY, Kim BG. Effects of enzyme supplementation on growth, intestinal content viscosity, and digestive enzyme activities in growing pigs fed rough rice-based diet. Asian-Aust J Anim Sci. 2008;21 (2):270-76.

3. Lindberg JE. Fiber effects in nutrition and gut health in pigs. J Anim Sci Biotechnol. 2014;5(1):15.

4. Li WF, Feng J, Xu ZR, Yang CM. Effects of non-starch polysaccharides enzymes on pancreatic and small intestinal digestive enzyme activities in piglet fed diets containing high amounts of barley. World J Gastroenterol. 2004;10(6):856-9.

5. Willamil J, Badiola I, Devillard E, Geraert PA, Torrallardona D. Wheat-barley-nyeor corn-fed growing pigs respond differently to dietary supplementation with a carbohydrase complex. J Anim Sci. 2012;90(3):824-32.

6. Susenbeth A, Naatjes M, Blank B, Kühl R, Ader P, Dickhoefer U. Effect of xylanase and glucanase supplementation to a cereal-based, threoninelimited diet on the nitrogen balance of growing pigs. Arch Anim Nutr. 2011;65(2):123-33

7. Prandini A, Sigolo S, Morlacchini M, Giuberti G, Moschini M, Rzepus M, et al. Addition of non-starch polysaccharides degrading enzymes to two hulless barley varieties fed in diets for weaned pigs. J Anim Sci. 2014;92(5):2080-6.

8. Kim JS, Ingale SL, Hosseindoust AR, Lee SH, Lee JH, Chae BJ. Effects of mannan level and $\beta$-mannanase supplementation on growth performance, apparent total tract digestibility and blood metabolites of growing pigs. Animal. 2016. doi:10.1017/S1751731116001385.

9. Guo S, Liu D, Zhao X, Li C, Guo Y. Xylanase supplementation of a wheatbased diet improved nutrient digestion and mRNA expression of intestinal nutrient transporters in broiler chickens infected with Clostridium perfringens. Poult Sci. 2014;93(1):94-103.

10. Lin PH, Shih BL, Hsu JC. Effects of different sources of dietary non-starch polysaccharides on the growth performance, development of digestive tract and activities of pancreatic enzymes in goslings. Br Poult Sci. 2010;51 (2):270-7.

11. Kiarie EG, Slominski BA, Nyachoti CM. Effect of products derived from hydrolysis of wheat and flaxseed non starch polysaccharides by carbohydrase enzymes on net absorption in enterotoxigenic Escherichia coli (K88) challenged piglet jejunal segments. Anim Sci J. 2010;81(1):63-71.

12. Aulrich $\mathrm{K}$, Flachowsky $\mathrm{G}$. Studies on the mode of action of non-starchpolysaccharides (NSP)-degrading enzymes in vitro. 2. Communication: effects on nutrient release and hydration properties. Arch Tierernahr. 2001; 54(1):19-32. 
13. Silva SS, Smithard RR. Effect of enzyme supplementation of a rye-based diet on xylanase activity in the small intestine of broilers, on intestinal crypt cell proliferation and on nutrient digestibility and growth performance of the birds. Br Poult Sci. 2002;43(2):274-82.

14. Balamurugan R, Chandrasekaran D, Kirubakaran A. Effects of multi-enzyme supplementation on gut morphology and histomorphology in broilers. Indian J Anim Sci. 2011;4(1):15-8.

15. Ao X, Meng QW, Yan L, Kim YH, Hong SM, Cho JH, et al. Effects of nonstarch polysaccharide-degrading enzymes on nutrient digestibility, growth performance and blood profiles of growing pigs fed a diet based on corn and soybean meal. Asian-Aust J Anim Sci. 2010;23(12):1632-8.

16. Kaput J, Rodriguez RL. Nutritional genomics: the next frontier in the postgenomic era. Physiol Genomics. 2004;16(2):166-77.

17. Astle J, Ferguson JT, German JB, Harrigan GG, Kelleher NL, Kodadek T, et al. Characterization of proteomic and metabolomic responses to dietary factors and supplements. J Nutr. 2007;137(12):2787-93.

18. Zhang JZ, Li DF. Effect of conjugated linoleic acid on inhibition of prolyl hydroxylase 1 in hearts of mice. Lipids Health Dis. 2012;11:22.

19. Wang JJ, Li DF, Dangott L, Wu GY. Proteomics and its role in nutrition research. J Nutr. 2006;136(7):1759-62.

20. Kitteringham NR, Abdullah A, Walsh J, Randle $L$, Jenkins RE, Sison $R$, et al. Proteomic analysis of Nrf2 deficient transgenic mice reveals cellular defence and lipid metabolism as primary Nrf2-dependent pathways in the liver. J Proteomics. 2010;73(8):1612-31.

21. Luo J, Zheng A, Meng $K$, Chang W, Bai Y, Li K, et al. Proteome changes in the intestinal mucosa of broiler (Gallus gallus) activated by probiotic Enterococcus faecium. J Proteomics. 2013;91:226-41.

22. Reichardt F, Habold C, Chaumande B, Ackermann A, Ehret-Sabatier L, Le Maho $Y$, et al. Interactions between ingested kaolinite and the intestinal mucosa in rat: proteomic and cellular evidences. Fundam Clin Pharmacol. 2009;23(1):69-79.

23. Lowe SE, Theodorou MK, Trinci AP. Cellulase and xylanase of an anaerobic rumen fugus grown on wheat straw, wheat straw holocellulose, cellulose, xylan. Appl Environ Microbiol. 1987;53(6):1216-23.

24. Gao Y, Zhou X, Yu JX, Jin YC, Li C, Liu JY, et al. Effects of non-starch polysaccharide enzymes addition on growth performance, carcass traits and meat quality of growing-finishing pigs. Chin J Vet Sci. 2014;34(5): 820-4 (In Chinese)

25. Wang X, Yang F, Liu C, Zhou H, Wu G, Qiao S, et al. Dietary supplementation with the probiotic Lactobacillus fermentum 15007 and the antibiotic aureomycin differentially affects the small intestinal proteomes of weanling piglets. J Nutr. 2012;142(1):7-13.

26. Olsen JV, Blagoev B, Gnad F, Macek B, Kumar C, Mortensen P, et al. Global, in vivo, and site-specific phosphorylation dynamics in signaling networks. Cell. 2006;127(3):635-48.

27. Su L, Cao L, Zhou R, Jiang Z, Xiao K, Kong W, et al. Identification of novel biomarkers for sepsis prognosis via urinary proteomic analysis using ITRAQ labeling and 2D-LC-MS/MS. PLoS One. 2013;8(1):e54237.

28. Hakimov HA, Walters S, Wright TC, Meidinger RG, Verschoor CP, Gadish M, et al. Application of iTRAQ to catalogue the skeletal muscle proteome in pigs and assessment of effects of gender and diet dephytinization. Proteomics. 2009;9(16):4000-16.

29. Long B, Yin C, Fan Q, Yan G, Wang Z, Li X, et al. Global liver proteome analysis using ITRAQ reveals AMPK-mTOR-autophagy signaling is altered by intrauterine growth restriction in newborn piglets. J Proteome Res. 2016;15(4):1262-73.

30. Zhang LZ, Yan WY, Wang ZL, Guo YH, Yi Y, Zhang SW. Differential protein expression analysis following olfactory learning in Apis cerana. J Comp Physiol A. 2015;201(11):1053-61.

31. Zhang J, Li C, Tang X, Lu Q, Sa R, Zhang H. High concentrations of atmospheric ammonia induce alterations in the hepatic proteome of broilers (Gallus gallus): an iTRAQ-based quantitative proteomic analysis. PLoS One. 2015;10(4):e0123596.

32. Kiarie $E$, Romero LF, Nyachoti CM. The role of added feed enzymes in promoting gut health in swine and poultry. Nutr Res Rev. 2013;26(1): 71-88.

33. Khadem A, Lourenço M, Delezie E, Maertens L, Goderis A, Mombaerts R, et al. Does release of encapsulated nutrients have an important role in the efficacy of xylanase in broilers? Poult Sci. 2016;95(5):1066-76.

34. Willamil J, Badiola JI, Torrallardona D, Geraert PA, Devillard E. Effect of enzyme supplementation on nutrient digestibility and microbial metabolite concentrations in ileal and caecal digesta of growing pigs. Book of abstracts of 11th International Symposium on Digestive Physiology of Pigs; 2009.
35. Zijlstra RT, Owusu-Asiedu A, Simmins PH. Future of NSP-degrading enzymes to improve nutrient utilization of co-products and gut health in pigs. Livest Sci. 2010;134(1-3):255-7.

36. Bakke-McKellep AM, Penn MH, Salas PM, Refstie S, Sperstad S, Landsverk T, et al. Effects of dietary soyabean meal, inulin and oxytetracycline on intestinal microbiota and epithelial cell stress, apoptosis and proliferation in the teleost Atlantic salmon (Salmo salar L.). Br J Nutr. 2007;97(4):699-713.

37. Dehghan-Kooshkghazi M, Mathers JC. Starch digestion, large-bowel fermentation and intestinal mucosal cell proliferation in rats treated with the alpha-glucosidase inhibitor acarbose. Br J Nutr. 2004;91(3):357-65.

38. Klejnot M, Gabrielsen M, Cameron J, Mleczak A, Talapatra SK, Kozielski F, et al. Analysis of the human cofilin 1 structure reveals conformational changes required for actin binding. Acta Crystallogr D Biol Crystallogr. 2013;69(Pt 9): 1780-8.

39. Nakano K, Kanai-Azuma M, Kanai Y, Moriyama K, Yazaki K, Hayashi Y, et al. Cofilin phosphorylation and actin polymerization by NRK/NESK, a member of the germinal center kinase family. Exp Cell Res. 2003;287(2):219-27.

40. Insall R, Müller-Taubenberger A, Machesky L, Köhler J, Simmeth E, Atkinson SJ, et al. Dynamics of the Dictyostelium Arp2/3 complex in endocytosis, cytokinesis, and chemotaxis. Cell Motil Cytoskeleton. 2001;50(3):115-28.

41. Hewitt EW. The MHC, class I antigen presentation pathway: strategies for viral immune evasion. Immunology. 2003;110(2):163-9.

42. Tomatsu S, Orii KO, Vogler C, Nakayama J, Levy B, Grubb JH, et al. Mouse model of N-acetylgalactosamine-6-sulfate sulfatase deficiency (Galns-/-) produced by targeted disruption of the gene defective in Morquio A disease. Hum Mol Genet. 2003;12(24):3349-58.

43. Settembre C, Fraldi A, Medina DL, Ballabio A. Signals from the lysosome: a control centre for cellular clearance and energy metabolism. Nat Rev Mol Cell Biol. 2013;14(5):283-96.

44. Takaoka A, Wang Z, Choi MK, Yanai H, Negishi H, Ban T, et al. DAI (DLM-1/ ZBP1) is a cytosolic DNA sensor and an activator of innate immune response. Nature. 2007:448(7152):501-5.

45. Hayashi T, Nishitsuji H, Takamori A, Hasegawa A, Masuda T, Kannagi M. DNAdependent activator of IFN-regulatory factors enhances the transcription of HIV-1 through NF-kB. Microbes Infect. 2010;12(12-13):937-47.

46. Levy M, Thaiss CA, Zeevi D, Dohnalová L, Zilberman-Schapira G, Mahdi JA, et al. Microbiota-modulated metabolites shape the intestinal microenvironment by regulating NLRP6 inflammasome signaling. Cell. 2015;163(6):1428-43.

47. Jia M, Jing $Y$, Ai Q, Jiang R, Wan J, Lin L, et al. Potential role of catalase in mice with lipopolysaccharide/D-galactosamine-induced fulminant liver injury. Hepatol Res. 2014;44(11):1151-8.

48. Spolarics $\mathrm{Z}, \mathrm{Wu}$ JX. Role of glutathione and catalase in $\mathrm{H}_{2} \mathrm{O}_{2}$ detoxification in LPS-activated hepatic endothelial and Kupffer cells. Am J Physiol. 1997; 273(6 Pt 1):G1304-11.

49. Lillig $\mathrm{CH}$, Berndt C, Holmgren A. Glutaredoxin systems. Biochim Biophys Acta. 2008;1780(11):1304-17.

50. Arnér ES, Holmgren A. Physiological functions of thioredoxin and thioredoxin reductase. Eur J Biochem. 2000;267(20):6102-9.

51. Khadem Ansari MH, Karimipour M, Salami S, Shirpoor A. The effect of ginger (Zingiber officinale) on oxidative stress status in the small intestine of diabetic rats. Int J Endocrinol Metab. 2008;6(3):144-50.

52. Fattman $\mathrm{CL}$, Schaefer LM, Oury TD. Extracellular superoxide dismutase in biology and medicine. Free Radic Biol Med. 2003;35(3):236-56.

53. Cashman JR, Zhang J. Human flavin-containing monooxygenases. Annu Rev Pharmacol Toxicol. 2006:46:65-100.

54. Schurig H, Beaucamp N, Ostendorp R, Jaenicke R, Adler E, Knowles JR. Phosphoglycerate kinase and triosephosphate isomerase from the hyperthermophilic bacterium Thermotoga maritima form a covalent bifunctional enzyme complex. EMBO J. 1995;14(3):442-51.

55. Costa E, Guidotti A. Diazepam binding inhibitor (DBI): a peptide with multiple biological actions. Life Sci. 1991;49(5):325-44.

56. Mori T, Kondo H, Hase T, Tokimitsu I, Murase T. Dietary fish oil upregulates intestinal lipid metabolism and reduces body weight gain in C57BL/6 J mice. J Nutr. 2007;137(12):2629-34.

57. Wang F, Kohan AB, Dong HH, Yang Q, Xu M, Huesman S, et al. Overexpression of apolipoprotein C-III decreases secretion of dietary triglyceride into lymph. Physiological Rep. 2014;2(3):e00247.

58. Shimizu M. Interaction between food substances and the intestinal epithelium. Biosci Biotechnol Biochem. 2010;74(2):232-41.

59. Tsukita S, Furuse M, Itoh M. Multifunctional strands in tight junctions. Nat Rev Mol Cell Biol. 2001;2(4):285-93. 
60. Karbach U. Paracellular calcium transport across the small intestine. J Nutr. 1992;122 Suppl 3:672-7.

61. Hisada N, Satsu H, Mori A, Totsuka M, Kamei J, Nozawa T, et al. Lowmolecular-weight hyaluronan permeates through human intestinal Caco-2 cell monolayers via the paracellular pathway. Biosci Biotechnol Biochem. 2008;72(4):1111-4

62. Bao YM, Choct M. Dietary NSP nutrition and intestinal immune system for broiler chickens. World Poultry Sci J. 2010. doi:10.1017/S0043933910000577.

63. Fernández-Fígares I, Wray-Cahen D, Steele NC, Campbell RG, Hall DD, Virtanen $E$, et al. Effect of dietary betaine on nutrient utilization and partitioning in the young growing feed-restricted pig. J Anim Sci. 2002;80(2):421-8.

64. Peacock M. Calcium metabolism in health and disease. Clin J Am Soc Nephrol. 2010. doi:10.2215/CJN.05910809.

65. Potters G. Systems biology of the cell. Nat Educ. 2010;3:33.

Submit your next manuscript to BioMed Central and we will help you at every step:

- We accept pre-submission inquiries

- Our selector tool helps you to find the most relevant journal

- We provide round the clock customer support

- Convenient online submission

- Thorough peer review

- Inclusion in PubMed and all major indexing services

- Maximum visibility for your research

Submit your manuscript at www.biomedcentral.com/submit
Biomed Central 